\title{
Mirror, mirror on the wall: the predictive value of mirror tests for measuring aggression in fish
}

\author{
Valentina Balzarini • Michael Taborsky • \\ Sandro Wanner • Felizia Koch • Joachim G. Frommen
}

Received: 28 November 2013 / Revised: 17 February 2014 / Accepted: 17 February 2014 / Published online: 8 March 2014

(C) Springer-Verlag Berlin Heidelberg 2014

\begin{abstract}
The behaviour of animals towards their mirror image ("mirror test") is routinely used as a proxy to measure aggression levels, especially in fish. The lack of evidence for visual self-recognition in fish supports this method. However, recent work points towards different hormonal and gene expression responses when fish are exposed either to conspecific opponents or to their mirror image, urging for validation of this widespread method. Here, we test the predictive value of mirror tests in three sympatric cichlid species from Lake Tanganyika: the cooperative breeder Neolamprologus pulcher, the polygamous shell brooder Telmatochromis vittatus and the monogamous, biparental piscivore Lepidiolamprologus elongatus. In particular, we compare differences in restrained and overt aggression levels for individuals of each species when confronted with a mirror or a live conspecific. The three species differed in response to the two contest situations. While in $N$. pulcher both aggressive responses were correlated between the mirror test and the live opponent fight, there was no such relationship in T. vittatus and $L$. elongatus. Thus, the mirror test appears to be a suitable surrogate for intraspecific aggression in N. pulcher, while aggression against a mirror image has limited predictive value for intraspecific aggression in the other two species. These results underline the importance of validating the mirror test's predictive value in a study species before drawing conclusions from mirror tests about aggressiveness under natural, social conditions.
\end{abstract}

Communicated by J. Lindström

V. Balzarini $(\bowtie) \cdot$ M. Taborsky $\cdot$ S. Wanner $\cdot$ F. Koch $\cdot$

J. G. Frommen

Department of Behavioural Ecology, Institute of Ecology and

Evolution, University of Bern, Wohlenstraße 50a,

3032 Hinterkappelen, Switzerland

e-mail: valentina.balzarini@iee.unibe.ch
Keywords Neolamprologus pulcher · Cichlid fish · Animal personality $\cdot$ Behavioural syndrome $\cdot$ Copying style

\section{Introduction}

Aggressive behaviour is a crucial component of inter- and intraspecific competition, and hence, it is quantified in many different contexts. Most often, aggression is measured in staged encounters between two individuals (e.g. Huntingford 1980; Dingemanse et al. 2007; Arnott and Elwood 2009), with or without physical barriers between contestants (e.g. Bakker and Sevenster 1983; Verbeek et al. 2007). However, the use of live opponents increases the variance of the test subject's behaviour due to individual differences in the opponent's aggressive response. A frequently used means to standardize an opponent's behaviours is to use a mirror instead of live conspecifics (e.g. Kusayama et al. 2000; Vøllestad and Quinn 2003). Here, a crucial prerequisite is the lack of selfrecognition in the test species. The ability to recognize oneself in a mirror image has been demonstrated only in few taxa (grey parrots, Psittacus erithacus, Pepperberg et al. 1995; different primates, de Veer and van den Bos 1999; Schilhab 2004; capuchin monkeys, Cebus apella, de Waal et al. 2005; magpies, Pica pica, Prior et al. 2008; elephants, Elephas maximus, Plotnik et al. 2010). In most animal taxa, it is instead assumed that individuals treat their mirror image as a conspecific (Gallup 1968; Andrews 1996).

If this assumption is justified, mirror tests seem valid to quantify individual aggressive behaviour (e.g. Lissmann 1932; Tinbergen 1951; Zajonc 1966; Gallup 1968; Andrews 1996), as each experimental subject is confronted with a conspecific perfectly matched in size that exhibits the exact same behaviour as the subject. Thus, the effect of the opponent's behaviour seems to be controlled for. Recently, however, researchers have questioned the assumptions underlying 
the use of mirror simulations (May and Mercier 2007; Hirschenhauser et al. 2008; Desjardins and Fernald 2010). An endocrinological study of Japanese quail (Coturnix japonica), for instance, showed markedly different hormonal responses towards a mirror image or a real opponent (Hirschenhauser et al. 2008), while in crayfish, dominant and subordinate individuals reacted differently to their mirror images (Drodz et al. 2006; May and Mercier 2007).

The use of mirrors is also widespread in studies of fish. Tinbergen (1951), for example, studied the response of male three-spined stickleback (Gasterosteus aculeatus) to their mirror image. A frequently used fish to study aggression using mirror simulations is the Siamese fighting fish Betta splendens, because of the intrinsic aggressiveness of this species (e.g. Lissmann 1932; Craft et al. 2003; Verbeek et al. 2007; Matessi et al. 2010). Here, recent studies have questioned the correspondence between conspecific fights and mirror simulations. Wild and domesticated strains of B. splendens differed in their behaviour during a conspecific fight, but not during mirror simulations (Verbeek et al. 2007). Furthermore, in Burton's mouthbrooder (Astatotilapia burtoni), differences in brain activity between these two staged encounter situations were described (Desjardins and Fernald 2010). These findings indicate that fish might discriminate between a conspecific and a mirror image, even if this ability may not be discernible by a simple behavioural test. Also, recent studies of opponent assessment (e.g. Van Dyk and Evans 2008) highlight the importance of coherent signal-response sequences during contests. Despite such reservations, mirrors continue to be used for tests of aggression in fish, especially in animal personality research (e.g. Boon et al. 2008; Riebli et al. 2011; Wilson et al. 2011). Often, the validity of this method has not been confirmed, and some studies have questioned its utility (cf. Earley et al. 2000; Arnott et al. 2011).

Here, we investigate the suitability of mirror simulations for tests of aggressive behaviour in three species of African cichlids. These fish show a wide array of aggressive behaviours, from aggressive displays to overt physical attacks (see Table 1). The three species are endemic to Lake Tanganyika (Fryer and Iles 1972; Witsenburg et al. 2010) and differ substantially in their social complexity. Neolamprologus pulcher (synonymous with Neolamprologus brichardi, Duftner et al. 2007) is a cooperative cave breeder. Populations are organized in colonies (Heg et al. 2005, 2008), each consisting of breeding groups of different sizes (2-25 individuals/group, Taborsky and Limberger 1981; Balshine et al. 2001; Heg et al. 2005). A breeding group includes a dominant pair and usually one or more subordinate helpers, organized in a size-dependent hierarchy (Hamilton et al. 2005) that is maintained by aggressive interactions (Mitchell et al. 2009). The level of individual aggression is frequently assessed with the help of a mirror test (Grantner and Taborsky 1998; Taborsky and Grantner 1998; Taves et al. 2009; Heg et al. 2011; Riebli et al. 2012). The response to mirror images has been shown to be a good proxy for overall aggression in this species (Reddon et al. 2012), but a detailed comparison of overt and restrained aggression between responses to mirror images and live conspecifics is missing thus far. The second species tested, Telmatochromis vittatus, is a polygynous species breeding in empty snail shells, with males exhibiting four different reproductive tactics (Ota and Kohda 2005). Territorial males defend nests inhabited by several females, and three different types of parasitic males try to steal

Table 1 Abbreviated ethogram used for the three species, with brief descriptions of the recorded behaviours

\begin{tabular}{|c|c|c|c|c|c|}
\hline \multirow[t]{2}{*}{ Aggression } & \multirow[t]{2}{*}{ Behaviour } & \multicolumn{3}{|c|}{ Species } & \multirow[t]{2}{*}{ Description } \\
\hline & & N.p. & T.v. & L.e. & \\
\hline \multirow[t]{2}{*}{ Overt } & Biting & $\mathrm{X}$ & $\mathrm{X}$ & $\mathrm{X}$ & Biting attempt, touching the mirror/partition \\
\hline & Ramming & $\mathrm{X}$ & $\mathrm{X}$ & $\mathrm{X}$ & Fast approach with physical contact to the mirror/partition, mouth closed \\
\hline \multirow[t]{8}{*}{ Restrained } & Fast approach & $\mathrm{X}$ & $\mathrm{X}$ & $\mathrm{X}$ & Swimming at high speed towards opponent, opercula are spread \\
\hline & Fin raise & $\mathrm{X}$ & $\mathrm{X}$ & $\mathrm{X}$ & All fins are maximally spread; fish is close to the opponent, either facing it or showing its side \\
\hline & S-bend & $\mathrm{X}$ & $\mathrm{X}$ & $\mathrm{X}$ & Body held stiffly in a bent position along the longitudinal axis \\
\hline & Opercula spread & $\mathrm{X}$ & - & $\mathrm{X}$ & Opercula spread when facing the opponent, but not combined with a fast approach movement \\
\hline & Head down & $\mathrm{X}$ & - & - & Body inclined downwards, up to $60^{\circ}$. Unpaired and pelvic fins are spread \\
\hline & Frontal swimming & - & $\mathrm{X}$ & - & $\begin{array}{l}\text { Swimming repeatedly back and forth along the mirror/partition, maintaining contact with } \\
\text { snout to the mirror }\end{array}$ \\
\hline & Parallel swimming & - & $\mathrm{X}$ & - & $\begin{array}{l}\text { Swimming repeatedly back and forth along mirror/partition, body parallel to mirror, at } \\
\text { close distance }\end{array}$ \\
\hline & Lateral display & - & $\mathrm{X}$ & $\mathrm{X}$ & Fish still for a while, showing lateral view to opponent, with fins spread \\
\hline
\end{tabular}

Behaviours expressed by a species are marked with $\mathrm{X}$

N.p. Neolamprologus pulcher, T.v. Telmatochromis vittatus, L.e. Lepidiolamprologus elongatus 
fertilizations. Tactic choice is strictly related to body size (Ota and Kohda 2005). The third species, Lepidiolamprologus elongatus, is a piscivore (Hori et al. 1983), breeding in monogamous pairs (Gashagaza 1991). Pairs vigorously defend eggs and young at their breeding site against conspecific and heterospecific intruders (Ochi and Yanagisawa 1998). Outside reproduction, L. elongatus sometimes hunt in loose fissionfusion shoals of various sizes (Konings 1998; Hori et al. 1983; MT and JGF, personal observation).

Using these three species, we investigate the relationship between the aggressive behaviour exhibited towards a mirror image or a live conspecific. We ask whether the mirror simulation provides reliable predictions for levels of individual aggression. The species chosen represent a range of different social organizations, from cooperatively breeding to solitary: this might provide hints on potential effects of social organization on the suitability of the mirror test.

\section{Methods}

\section{Subjects and holding conditions}

We used laboratory-bred first- or second-generation offspring of wild-caught individuals of $N$. pulcher, $T$. vittatus and L. elongatus. Fish were kept in 200-400-1 tanks, in nonbreeding aggregations of 20-30 fish each, mixed by size and sex. Fish of all three species were prevented from forming territories in these holding tanks by depriving them of breeding substrate. Tanks were aerated and filtered by an internal filter. The water temperature was stabilized at $27 \pm 2{ }^{\circ} \mathrm{C}$, with a 13:11 light/dark cycle. All fish were fed in excess once a day on 6 days per week, 5 days with flake food and 1 day with a defrosted live food mix. On the day of experiment, subjects and stimulus fish were fed after the last trial. Experiments were conducted in March and June 2012. We used 12 subjects and 12 opponents of each species, randomly chosen according to sex, from different stock tanks. Each subject was tested twice, once against a mirror image and once against a live opponent.

\section{Experimental procedure}

The mirror and opponent tests were conducted in the same tank, and experiments were done in parallel in four identical glass tanks measuring $100 \times 50 \times 40 \mathrm{~cm}$. The tanks were filled to a height of $25 \mathrm{~cm}$ with tap water, and the bottom was covered with $1 \mathrm{~cm}$ of sand. Water was filtered using an internal biological filter and additionally aerated with two air stones. The tank was divided into two parts measuring 53 and $47 \mathrm{~cm}$ using a transparent Plexiglas sheet. The bigger of these compartments was not used in the experiments. The smaller part, measuring $47 \times 50 \times 40 \mathrm{~cm}$, was divided into two compartments of 20 and $27 \mathrm{~cm}$ in length, respectively (see Fig. 1).

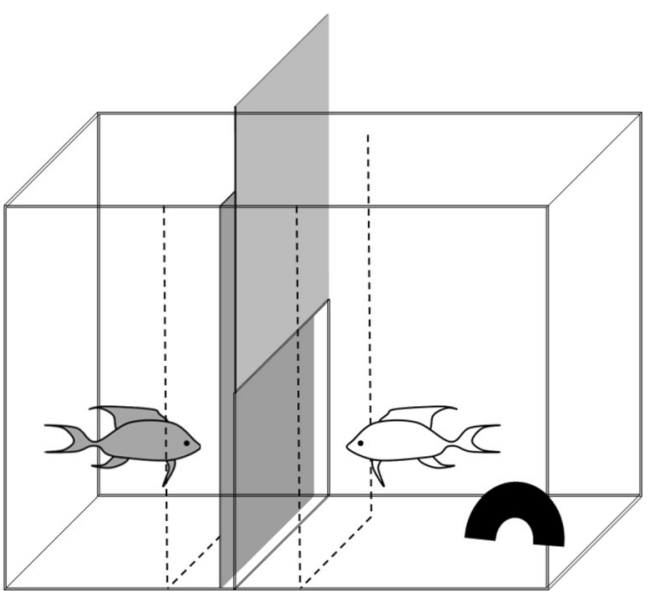

Fig. 1 Experimental set-up. The focal compartment with the shelter (flowerpot half, in black) is on the right side, with a sliding partition that reveals the mirror or to the opponent's compartment (left, grey fish). The dashed lines indicate the zone "in front" of the mirror or of the opponent used for behavioural recordings

The bigger of these compartments was used for the test fish and was equipped with half a flowerpot as a refuge in a corner, with the opening oriented at a $45^{\circ}$ angle towards the smaller compartment. This not only allowed the subject to hide but also minimized the time needed for the subject to realize the intruder threat. The smaller compartment served as the intruder tank in the opponent test. The compartments were separated from each other by an opaque partition that was removed during trials. In its place, either the mirror (mirror test) or a transparent Plexiglas partition (opponent test) was inserted.

Subjects were caught and standard length (SL) was measured to the nearest millimetre in the afternoon (1500 to 1600 hours) before the day of the experiment. $N$. pulcher test individuals measured 40-58 mm SL, T. vittatus test individuals 31-48 mm SL and L. elongatus test individuals 36$55 \mathrm{~mm}$ SL. For the first two species, the size range used represents adult individuals, while for $L$. elongatus all individuals were subadults. This allowed us to test all three species with the same tank size and experimental set-up; adult L. elongatus are much bigger and might require a different set-up. We confirmed in pilot observations that within the size range at which L. elongatus were tested in our experiment, the full range of aggressive behaviours typical of the species is already shown. After introduction, the test fish were allowed to acclimatize overnight. The first test started at 0900 hours on the following day. Subjects of each species were tested in the mirror trial and the opponent trial in random order and on the same day, with a 3-h break between the two tests.

The mirror or Plexiglas partition was inserted behind the opaque partition $30 \mathrm{~min}$ before the start of the trial. In the opponent test, stimulus fish were chosen at random from the holding tank and assigned to a contestant matching in size, with a maximum difference $<10 \%$ of the subject's standard 
length. Subjects and stimulus fish came from different holding tanks, to prevent familiarity effects (Frostman and Sherman 2004). Each test fish was confronted with a different stimulus fish. The stimulus fish was moved to its compartment just after inserting the clear Plexiglas partition. In both trials, the opaque barrier was lifted after a 30-min acclimation period, which exposed a $50 \times$ $20 \mathrm{~cm}(l \times h)$ window to the subject showing the mirror or the opponent. The behaviour of the subject and of the live opponent was measured for $20 \mathrm{~min}$ after removing the opaque partition.

\section{Behavioural assessment}

For each species, aggressive behaviours were recorded using the Noldus Observer 5.0 software (see Table 1 for details). Overall, three different measures were taken: overt aggression, restrained aggression and time spent close to the intruder. Overt aggressive behaviours were defined as biting attempts and as ramming events against the clear partition or the mirror (see Schürch and Heg 2010). The behaviours included in the restrained aggression category differed slightly among species (Table 1). N. pulcher behaviours were defined according to an established ethogram, summarized in Hamilton et al. (2005, modified from Taborsky 1984). As no description of aggressive behaviour was available for $T$. vittatus and $L$. elongatus, we established an ethogram for both species prior to the experiments (see Table 1). All aggressive behaviours were counted as events. For an overall "overt aggression" measure, the number of overt attacks was summed. The same was done for "restrained aggression", by combining the number of displays (Schürch and Heg 2010). Finally, "time in the frontal zone" was measured, defined as the time spent by the subject in the $6.5 \mathrm{~cm}$ closest to the compartment barrier (see also Mehlis et al. 2009). This zone was delimited by markings on the outside of the tank.
Statistical analyses

For each species, overt aggression, restrained aggression and time spent in the frontal zone were analyzed separately. As most data were not normally distributed according to KolmogorovSmirnov tests with Lilliefors correction, non-parametric statistics were used. Technical problems occurred during trials of one $N$. pulcher and two T. vittatus, which could thus not be analyzed. Spearman rank correlation tests were used to relate aggression towards the mirror with aggression towards the opponent. Wilcoxon matched-pairs signed-ranks tests were used to analyze the differences between aggression towards the mirror and aggression towards the live opponent. The potential effect of the opponent's behaviour on the subject's behaviour was also analyzed with a Spearman rank correlation test. Analyses were conducted using R 3.0.1 (R Development Core Team 2013). All given $p$-values are based on two-tailed tests.

\section{Results}

In N.pulcher, all three behavioural measures were significantly correlated between mirror and opponent tests (Spearman rank correlation, $N=11$, overt aggression $r_{\mathrm{s}}=0.72, p=0.01$; restrained aggression $r_{\mathrm{s}}=0.65, p=0.03$; time in the frontal zone $r_{\mathrm{s}}=0.78, p=0.004$; Fig. 2). Test fish showed a higher number of restrained aggressive displays against a live opponent than against the mirror (Wilcoxon matched-pairs signed-ranks test, $N=11, V=1, p=0.013$ ) (Fig. 3). Overt aggression and time spent in the frontal zone did not differ significantly between experimental conditions, though there was a trend for the time spent in the frontal zone to be higher when confronted with an opponent than with their mirror image (Wilcoxon matchedpairs signed-ranks test, $V=15, p=0.73$ and $V=6, p=0.06$, respectively; Fig. 3). In the opponent test, the subject's behaviour was significantly correlated with the opponent's overt and restrained aggression (Spearman rank correlation, $N=11$, overt

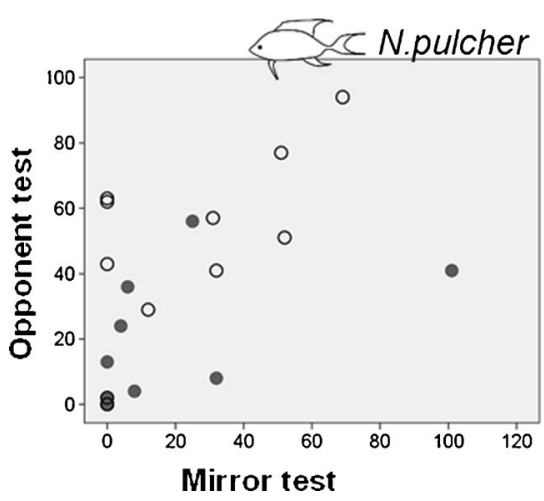

Fig. 2 Correlations of aggressive behaviours against a mirror and against a live opponent shown by (left to right) $N$. pulcher, T. vittatus and L. elongatus. Overt aggression is shown in grey, restrained aggression
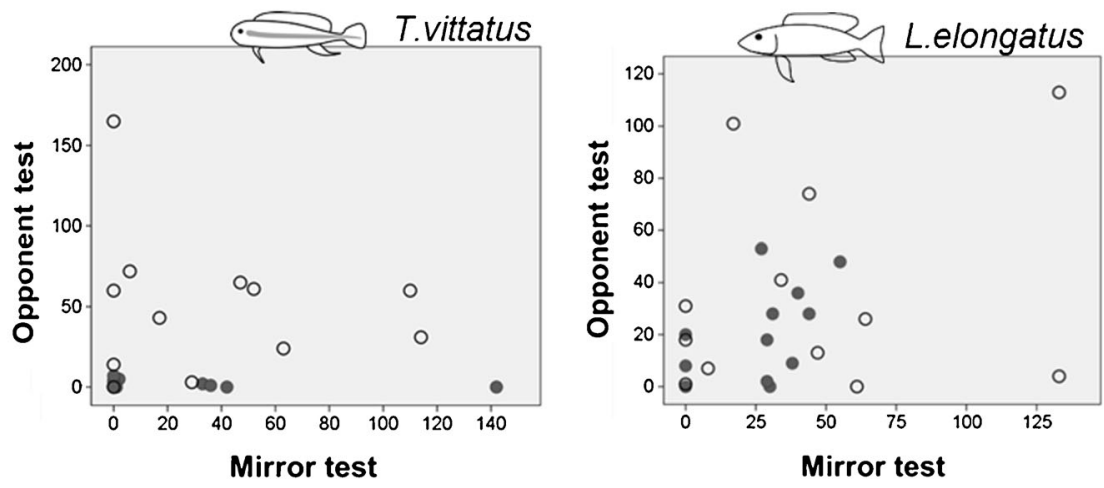

in white. Overt and restrained aggression were significantly correlated across contexts only in $N$. pulcher (see text for statistical results) 


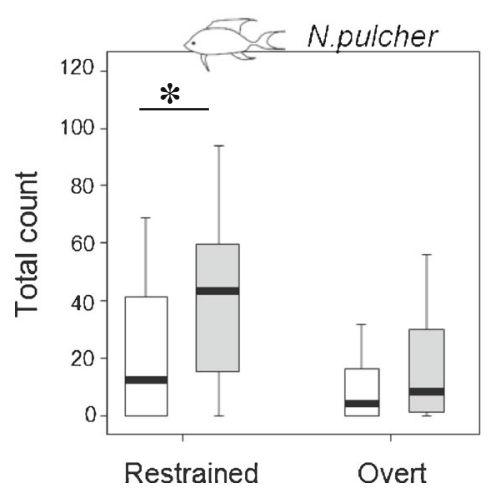

Fig. 3 Medians, quartiles and ranges for overt and restrained aggression towards a mirror (white) and towards a live opponent (grey). N. pulcher showed a higher amount of restrained aggression towards a live
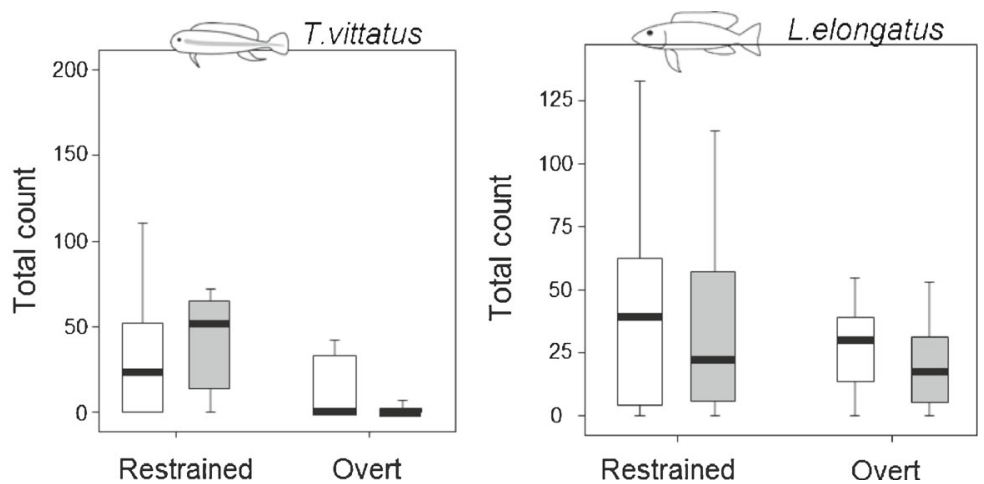

conspecific than towards a mirror image, while the behaviour of L. elongatus and T. vittatus did not differ between tests. The asterisk indicates significance $(p<0.05)$

\section{Discussion}

aggression $r_{\mathrm{s}}=0.76, p=0.007$; restrained aggression $r_{\mathrm{s}}$ ship between the two fish regarding the time spent in the frontal zone (Spearman rank correlation, $N=11, r_{\mathrm{s}}=$ $0.48, p=0.14$ ).

In T. vittatus, none of the three behavioural measures were significantly correlated between contexts (Spearman rank correlation, $N=10$, overt aggression $r_{\mathrm{s}}=-0.42, p=0.23$; restrained aggression $r_{\mathrm{s}}=0.079, p=0.83$; time in the frontal zone $r_{\mathrm{s}}=0.134, p=0.71 ;$ Fig. 2 ). The amount of overt and restrained aggression as well as the time spent in the frontal zone was not significantly different between tests (Wilcoxon matched-pairs signed-ranks test $N=10$, overt aggression $V=25.5, p=0.77$; restrained aggression $V=17.5, p=0.59$; time in the frontal zone $V=15, p=0.41$; Fig. 3 ). In the opponent test, the subject's behaviour did not significantly correlate with the opponent's overt and restrained aggression, but the time spent in the frontal zone was significantly correlated between the two fish (Spearman rank correlation, $N=10$, overt aggression $r_{\mathrm{s}}=-0.089, p=0.81$; restrained aggression $r_{\mathrm{s}}=0.115, p=$ 0.76 ; time in the frontal zone $r_{\mathrm{s}}=0.87, p=0.003$ ).

In $L$. elongatus, there were no significant behavioural correlations between the different contexts (Spearman rank correlation, $N=12$, overt aggression $r_{\mathrm{s}}=0.46, p=0.14$; restrained aggression $r_{\mathrm{s}}=0.08, p=0.8$; time in the frontal zone $r_{\mathrm{s}}=0.29, p=0.37$; Fig. 2). There were no significant differences between the number of behavioural displays or the time spent in the frontal zone between the mirror and the opponent trials (Wilcoxon matched-pairs signed-ranks test, $N=12$, overt aggression $V=47, p=0.23$; restrained aggression $V=45.5, p=$ 0.64 ; time in the frontal zone $V=20, p=0.27$; Fig. 3). In the opponent test, restrained aggression and time spent in the frontal zone by the subject and by the opponent correlated significantly with each other, whereas this correlation only approached significance in overt aggression (Spearman rank correlation, $N=12$, overt aggression $r_{\mathrm{s}}=0.55, p=0.065$; restrained aggression $r_{\mathrm{s}}=0.75, p=0.005$; time in the frontal zone $\left.r_{\mathrm{s}}=0.64, p=0.02\right)$.
This study aimed to validate the use of mirror tests as a reliable estimate of individual aggression in three sympatric species of Lake Tanganyika cichlids. Individuals of each species were tested for aggression against a conspecific intruder and against a mirror image, comparing three measures: overt and restrained aggression and time spent close to the opponent. The three species responded differently to the two experimental situations. While in $N$. pulcher all measures were correlated across contexts, no significant correlations were found in L. elongatus and T. vittatus. Furthermore, the behaviour of all species was at least partly influenced by the respective opponent's behaviour, with aggression of the two individuals significantly correlated with each other. Specifically, in $N$. pulcher, the opponent's behaviour had an influence on the test fish's restrained and overt aggression, while in L. elongatus, the correlation was significant for restrained aggression and time in the frontal zone, with a trend in the same direction for overt aggression. In T. vittatus, the opponent's influence was restricted to the time spent in the frontal zone. Finally, $N$. pulcher showed more restrained aggression towards the opponent than towards their mirror image.

\section{Validity of mirror simulation}

The correlation of behaviours across contexts as estimated in this study is a measure of phenotypic correlation (sensu Dingemanse et al. 2012), which justifies the use of one of the two measures as a proxy for the other. In the present case, a significant correlation between aggressive behaviours expressed towards a mirror and during a conspecific fight implies that the former measure can be used as a reliable predictor of the latter.

Our results show that the predictive value of mirror simulations is species specific. In N. pulcher, the strong correlation of all three behavioural measures between mirror and opponent tests confirms the validity of using mirror simulations to 
estimate individual aggression. This result is in concordance with a recent study of Reddon et al. (2012), who analyzed overall aggressive responses to these two types of stimuli. It confirms that the use of mirror images to release and estimate aggression in this species is appropriate (Grantner and Taborsky 1998; Chervet et al. 2011; Riebli et al. 2011, 2012). In contrast, in $T$. vittatus and L. elongatus, no significant behavioural correlations were found across tests, making mirror simulations unsuitable for estimating individual aggression. The behavioural variability expressed by the three species and their different responses to the two competitor simulations highlight the importance of validating mirror tests for their suitability to obtain representative estimates of individual aggression, for each species separately. This is emphasized by the fact that the three species studied here are phylogenetically related; they are all substrate breeding fish belonging to the Lake Tanganyika cichlid tribe Lamprologini (Sturmbauer et al. 1994).

\section{Across-context differences}

$N$. pulcher test subjects performed significantly more restrained aggressive displays against conspecific opponents than against a mirror image, whereas the aggressive behaviour of $T$. vittatus and $L$. elongatus test subjects did not differ between the exposure to a live conspecific intruder and their mirror image. The different reaction of $N$. pulcher to the two stimuli might indicate different stimulus perception. A mirror image shows exactly the same aggressive behaviour as the test subject, thus presenting a response that is not coherent with the behaviour expressed by the subject. In contrast, a live opponent's response to a signal should accord with its intensity, allowing for more accurate assessment of the opponent's strength and motivation. Such effects have been recently compared in lizards. Van Dyk and Evans (2008) manipulated the signalling strategy of a video-animated lizard to test for the effect of matching or mismatching responses to the signals given by the experimental subject. The tested lizards showed more overt attacks against the video animation in the "mirror strategy" treatment, where the video image showed exactly the same behaviours as those performed by the test individual, than if the response of the video image was appropriate to the signal given by the test individuals (e.g. submission following an aggressive display).

\section{Interspecific differences}

The differences in behavioural responses found among the three tested species might indicate that the social structure of a species affects an individual's response to a conspecific. The two predatory species $T$. vittatus and L. elongatus do not live in stable groups but only engage in temporary social bonds during reproduction and brood care (Ochi and Yanagisawa
1998; Ota and Kohda 2005). In contrast, $N$. pulcher groups are stable and highly structured over time, with group membership being of paramount importance for survival and reproductive success (e.g. Taborsky and Limberger 1981; Taborsky 1984; Balshine et al. 2001; Heg et al. 2005). Group members in $N$. pulcher react strongly to conspecific intruders that might threaten their position in the hierarchy (Taborsky 1985; Bruintjes and Taborsky 2008). The position of helpers in the hierarchy is strongly determined by body size, making similar-sized fish a particular challenge (Hamilton et al. 2005). The threat perceived in front of a mirror image might therefore be particularly strong, because the simulated intruder is exactly the same size as the test individual, and thus likely to challenge the focal individual's social position. In contrast, T. vittatus and L. elongatus do not defend permanent territories, and therefore, intruders only pose a threat during reproduction, i.e. as reproductive competitors or potential offspring predators. In addition, the shelter provided in our experiment might not have the same ecological value for these two species as it has for $N$. pulcher, which uses such shelters permanently for hiding and breeding. It is possible that T. vittatus and L. elongatus might differentiate between opponent types only when the value of the defended resource is higher than in our experimental situation, e.g. in a truly reproductive context (see, for example, Gherardi 2006; Arnott and Elwood 2008; Stockermans and Hardy 2013).

Another possible reason for the different reactions of the three species might be their divergent behavioural repertoires, especially regarding restrained aggression. The most striking behavioural difference exists between $N$. pulcher and T. vittatus: the former species relies mainly on frontal displays such as "opercular spread", whereas the latter shows more lateral displays like "parallel swimming" (Table 1). In interactions between live fish, often lateral displays are shown in an antiparallel way (the two fish heading in opposite directions, head to tail) (e.g. Brawn 1961; Keenleyside and Yamamoto 1962; Constanz 1975; Arnott et al. 2011). This pattern is disrupted by the mirror image, which is head-tohead to the test subject, creating a potentially confusing signal (Arnott et al. 2011). As frontal displays are perfectly reflected by the mirror, $N$. pulcher facing a mirror "opponent" may not be exposed to such signal disruption.

Whatever the cause of the interspecific differences found in this study, a comparison between only three species does not allow drawing conclusions on underlying mechanisms. This requires a much larger sample of different species. Before such comparative data exist to identify crucial factors responsible for the reliability of a mirror test in estimating aggressive responses against social partners, our study highlights the importance to acquire comparative information about the behaviour of experimental subjects towards mirror images and live conspecifics for each species or study system separately. 
Further prudence should be exercised because the predictive value of the mirror test might depend on the situation. For example, the validity of the mirror test might change depending on the age, sex and reproductive state of an individual. In social species, reactions of a single individual and of an individual within a group towards a mirror image might differ depending on social status or on the behaviour of other group members. Furthermore, it should be stressed that precaution has to be taken also when interpreting direct tests of aggression between social partners that do not allow for direct physical contact between the contestants, e.g. if interacting partners are separated by a glass partition. If only limited information (e.g. visual cues) is available to contestants in a social context, the resulting behaviour may differ from situations where all relevant information would be on hand.

\section{Conclusion}

Overall, the three species of sympatric cichlids tested in this study showed divergent responses to mirror images and live conspecifics, differing both in discrimination between and consistency across contexts. The different reactions among $N$. pulcher, T. vittatus and L. elongatus indicate that mirror simulations can be, but are not necessarily, an adequate proxy for individual aggression in a natural contest, suggesting that this method should be validated for each species before experimental application.

Acknowledgments We are grateful to the members of the $2012 \mathrm{Be}-$ havioural Ecology class for discussions and to Pierpaolo Brena for his help during the experiments. We thank Evi Zwygart and the members of the Behavioural Ecology Division for helping to breed and rear the test fish. We thank Bob Elwood and two anonymous reviewers for the thoughtful comments on the manuscript. VB was partly funded by SNF grant no. 31003A_144191 to JGF. We acknowledge receipt of a poster prize for the presentation of the study underlying this publication at the 14th Congress of the International Society for Behavioural Ecology, Lund, Sweden (2012).

Ethical standards The experiments followed the "ABS/ASAB guidelines for the treatment of animals in behavioural research and teaching" and comply with the current laws of Switzerland (licence number $\mathrm{BE} 52 / 12)$.

Conflict of interest The authors declare that they have no conflict of interest.

\section{References}

Andrews E (1996) Slate-colored junco response to mirror. Bird-Banding 37:206

Arnott G, Elwood RW (2008) Information gathering and decision making about resource value in animal contests. Anim Behav 76:529-542

Arnott G, Elwood R (2009) Probing aggressive motivation in a cichlid fish. Biol Lett 5:762-764
Arnott G, Ashton C, Elwood RW (2011) Lateralization of lateral displays in convict cichlids. Biol Lett 7:683-685

Bakker TCM, Sevenster P (1983) Determinants of dominance in male sticklebacks (Gasterosteus aculeatus L.). Behaviour 86:55-71

Balshine S, Leach B, Neat F, Reid H, Taborsky M, Werner N (2001) Correlates of group size in a cooperatively breeding cichlid fish (Neolamprologus pulcher). Behav Ecol Sociobiol 50:134-140

Boon AK, Reale D, Boutin S (2008) Personality, habitat use, and their consequences for survival in North American red squirrels Tamiasciurus hudsonicus. Oikos 117:1321-1328

Brawn VM (1961) Aggressive behaviour in the cod (Gadus calalris L.). Behaviour 18:107-147

Bruintjes R, Taborsky M (2008) Helpers in a cooperative breeder pay a high price to stay: effects of demand, helper size and sex. Anim Behav 75:1843-1850

Chervet N, Zöttl M, Schürch R, Taborsky M, Heg D (2011) Repeatability and heritability of behavioural types in a social cichlid. Int J Evol Biol 2011:321729

Constanz GD (1975) Behavioural ecology of mating in the male Gila topminnow, Poecilipsis occidentalis (Cyprinodontiformes: Poeciliidae). Ecology 56:966-973

Craft BB, Velkey AJ, Szalda-Petree A (2003) Instrumental conditioning of choice behavior in male Siamese fighting fish (Betta splendens). Behav Process 63:171-175

de Veer MW, van den Bos R (1999) A critical review of methodology and interpretation of mirror self-recognition research in nonhuman primates. Anim Behav 58:459-468

Desjardins JK, Fernald RD (2010) What do fish make of mirror images? Biol Lett 6:744-747

Dingemanse NJ, Wright J, Kazem AJN, Thomas DK, Hickling R, Dawnay N (2007) Behavioural syndromes differ predictably between 12 populations of three-spined stickleback. J Anim Ecol 76:1128-1138

Dingemanse NJ, Dochtermann NA, Nakagawa S (2012) Defining behavioural syndromes and the role of "syndrome deviation" in understanding their evolution. Behav Ecol Sociobiol 66:1543-1548

Drodz JK, Viscek J, Brudzynski SM, Mercier JA (2006) Behavioral responses of crayfish to a reflective environment. J Crustac Biol $26: 463-473$

Duftner N, Sefc KM, Koblmüller S, Salzburger W, Taborsky M, Sturmbauer C (2007) Parallel evolution of facial stripe patterns in the Neolamprologus brichardi/pulcher species complex endemic to Lake Tanganyika. Mol Phylogenet Evol 45:706-715

Earley RL, Hsu Y, Wolf LL (2000) The use of standard aggression testing methods to predict combat behaviour and contest outcome in Rivulus marmoratus dyads (Teleostei: Cyprinodontidae). Ethology 106:743-761

Frostman P, Sherman PT (2004) Behavioral response to familiar and unfamiliar neighbors in a territorial cichlid, Neolamprologus pulcher. Ichthyol Res 51:283-285

Fryer G, Iles TD (1972) Cichlid fishes of the great lakes of Africa: their biology and evolution. Oliver and Boyd, Edinburgh

Gallup GG (1968) Mirror-image stimulation. Psychol Bull 70:782-793

Gashagaza M (1991) Diversity of breeding habits in lamprologini cichlids in Lake Tanganyika. Physiol Ecol Japan 28:29-65

Gherardi F (2006) Fighting behavior in hermit crabs: the combined effect of resource-holding potential and resource value in Pagurus longicarpus. Behav Ecol Sociobiol 59:500-510

Grantner A, Taborsky M (1998) The metabolic rates associated with resting, and with the performance of agonistic, submissive and digging behaviours in the cichlid fish Neolamprologus pulcher (Pisces: Cichlidae). J Comp Physiol 168:427-433

Hamilton IM, Heg D, Bender N (2005) Size differences within a dominance hierarchy influence conflict and help in a cooperatively breeding cichlid. Behaviour 142:1591-1613 
Heg D, Brouwer L, Bachar Z, Taborsky M (2005) Large group size yields group stability in the cooperatively breeding cichlid Neolamprologus pulcher. Behaviour 142:1615-1641

Heg D, Heg-Bachar Z, Brouwer L, Taborsky M (2008) Experimentally induced helper dispersal in colonially breeding cooperative cichlids. Environ Biol Fish 83:191-206

Heg D, Schürch R, Rothenberger S (2011) Behavioral type and growth rate in a cichlid fish. Behav Ecol 22:1227-1233

Hirschenhauser K, Wittek M, Johnston P, Möstl E (2008) Social context rather than behavioral output or winning modulates post-conflict testosterone responses in Japanese quail (Coturnix japonica). Physiol Behav 95:457-463

Hori M, Yamaoka K, Tamakura K (1983) Abundance and microdistribution of cichlid fishes on a rocky shore of Lake Tanganyika. Afr Study Monogr 3:25-38

Huntingford FA (1980) A review of the methods used to describe and measure aggressive behaviour in physiological studies. Aggress Behav 6:205-215

Keenleyside MHA, Yamamoto FT (1962) Territorial behaviour of juvenile Atlantic salmon (Salmo salar L.). Behaviour 19:139-169

Konings A (1998) Tanganyika cichlids in their natural habitat. Cichlid Press, El Paso, USA

Kusayama T, Bischof H, Watanabe S (2000) Responses to mirror-image stimulation in jungle crows (Corvus macrorhynchos). Anim Cogn 3: $61-64$

Lissmann H (1932) Die Umwelt des Kampffisches (Betta splendens Regan). Z Vergl Physiol 18:65-111

Matessi G, Matos RJ, Peake TM, Mcgregor PK, Dabelsteen T (2010) Effects of social environment and personality on communication in male Siamese fighting fish in an artificial network. Anim Behav 79:43-49

May HY, Mercier JA (2007) Duration of socialization influences responses to a mirror: responses of dominant and subordinate crayfish diverge with time of pairing. J Exp Biol 210:44284436

Mehlis M, Bakker TCM, Langen K, Frommen JG (2009) Cain and Abel reloaded? Kin recognition and male-male aggression in three-spined sticklebacks Gasterosteus aculeatus L. J Fish Biol 75:2154-2162

Mitchell JS, Jutzeler E, Heg D, Taborsky M (2009) Dominant members of cooperatively-breeding groups adjust their behaviour in response to the sexes of their subordinates. Behaviour 146:1665-1686

Ochi H, Yanagisawa Y (1998) Commensalism between cichlid fishes through differential tolerance of guarding parents towards intruders. J Fish Biol 52:985-996

Ota K, Kohda M (2005) Description of alternative male reproductive tactics in a shell-brooding cichlid, Telmatochromis vittatus, in Lake Tanganyika. J Ethol 24:9-15

Pepperberg IM, Garcia SE, Jackson EC, Marconi S (1995) Mirror use by African grey parrots (Psittacus erithacus). J Comp Psychol 109: $182-195$

Plotnik JM, de Waal FBM, Moore D, Reiss D (2010) Self-recognition in the Asian elephant and future directions for cognitive research with elephants in zoological settings. Zoo Biol 29:179-191

Prior H, Schwarz A, Gu O, Güntürkün O (2008) Mirror-induced behavior in the magpie (Pica pica): evidence of self-recognition. PLoS Biol 6:e202
R Development Core Team (2013) R: a language and environment for statistical computing. R Foundation for Statistical Computing 1:409, http://cran.r-project.org/

Reddon AR, O'Connor CM, Marsh-Rollo SE, Balshine S (2012) Effects of isotocin on social responses in a cooperatively breeding fish. Anim Behav 84:753-760

Riebli T, Avgan B, Bottini A, Duc C, Taborsky M, Heg D (2011) Behavioural type affects dominance and growth in staged encounters of cooperatively breeding cichlids. Anim Behav 81:313-323

Riebli T, Taborsky M, Chervet N, Apolloni N, Zürcher Y, Heg D (2012) Behavioural type, status and social context affect behaviour and resource allocation in cooperatively breeding cichlids. Anim Behav 84:925-936

Schilhab TSS (2004) What mirror self-recognition in nonhumans can tell us about aspects of self. Biol Philos 19:111-126

Schürch R, Heg D (2010) Life history and behavioral type in the highly social cichlid Neolamprologus pulcher. Behav Ecol 21:588-598

Stockermans BC, Hardy ICW (2013) Subjective and objective components of resource value additively increase aggression in parasitoid contests. Biol Lett 9:20130391

Sturmbauer C, Verheyen E, Meyer A (1994) Mitochondrial phylogeny of the Lamprologini, the major substrate spawning lineage of cichild fishes from Lake Tanganyika in eastern Africa. Mol Biol Evol 11: 691-703

Taborsky M (1984) Broodcare helpers in the cichlid fish Lamprologus brichardi: their costs and benefits. Anim Behav 32:1236-1252

Taborsky M (1985) Breeder-helper conflict in a cichlid fish with broodcare helpers: an experimental analysis. Behaviour 95:45-75

Taborsky M, Grantner A (1998) Behavioural time-energy budgets of cooperatively breeding Neolamprologus pulcher (Pisces: Cichlidae). Anim Behav 56:1375-1382

Taborsky M, Limberger D (1981) Helpers in fish. Behav Ecol Sociobiol 8:143-145

Taves MD, Desjardins JK, Mishra S, Balshine S (2009) Androgens and dominance: sex-specific patterns in a highly social fish (Neolamprologus pulcher). Gen Comp Endocrinol 161:202-207

Tinbergen N (1951) The study of instinct. Clarendon/Oxford University Press, New York

Van Dyk DA, Evans CS (2008) Opponent assessment in lizards: examining the effect of aggressive and submissive signals. Behav Ecol 19:895-901

Verbeek P, Iwamoto T, Murakami N (2007) Differences in aggression between wild-type and domesticated fighting fish are context dependent. Anim Behav 73:75-83

Vøllestad LA, Quinn TP (2003) Trade-off between growth rate and aggression in juvenile coho salmon, Oncorhynchus kisutch. Anim Behav 66:561-568

Waal FBM D, Dindo M, Freeman CA, Hall MJ (2005) The monkey in the mirror: hardly a stranger. Proc Natl Acad Sci U S A 102:11140 11147

Wilson AJ, de Boer M, Arnott G, Grimmer A (2011) Integrating personality research and animal contest theory: aggressiveness in the green swordtail Xiphophorus helleri. PLoS ONE 6:e28024

Witsenburg F, Schürch R, Otti O, Heg D (2010) Behavioural types and ecological effects in a natural population of the cooperative cichlid Neolamprologus pulcher. Anim Behav 80:757-767

Zajonc R (1966) Social psychology: an experimental approach. Belmont 